\title{
Timing of noninvasive ventilation failure: causes, risk factors, and potential remedies
}

\author{
Ezgi Ozyilmaz ${ }^{1}$, Aylin Ozsancak Ugurlu² and Stefano Nava ${ }^{3^{*}}$
}

\begin{abstract}
Background: Identifying the predictors of noninvasive ventilation (NIV) failure has attracted significant interest because of the strong link between failure and poor outcomes. However, very little attention has been paid to the timing of the failure. This narrative review focuses on the causes of NIV failure and risk factors and potential remedies for NIV failure, based on the timing factor.

Results: The possible causes of immediate failure (within minutes to $<1 \mathrm{~h}$ ) are a weak cough reflex, excessive secretions, hypercapnic encephalopathy, intolerance, agitation, and patient-ventilator asynchrony. The major potential interventions include chest physiotherapeutic techniques, early fiberoptic bronchoscopy, changing ventilator settings, and judicious sedation. The risk factors for early failure (within 1 to $48 \mathrm{~h}$ ) may differ for hypercapnic and hypoxemic respiratory failure. However, most cases of early failure are due to poor arterial blood gas (ABGs) and an inability to promptly correct them, increased severity of illness, and the persistence of a high respiratory rate. Despite a satisfactory initial response, late failure (48 h after NIV) can occur and may be related to sleep disturbance.
\end{abstract}

Conclusions: Every clinician dealing with NIV should be aware of these risk factors and the predicted parameters of NIV failure that may change during the application of NIV. Close monitoring is required to detect early and late signs of deterioration, thereby preventing unavoidable delays in intubation.

Keywords: Noninvasive ventilation, Treatment failure, Respiratory insufficiency

\section{Review}

The utilization of noninvasive mechanical ventilation (NIV) has become one of the most important developments in the field of mechanical ventilation over the past two decades. The use of NIV during acute respiratory failure (ARF) has increased since the late 1990s for all diagnoses, including patients with and without chronic obstructive pulmonary disease (COPD), regardless of the supporting evidence for the later [1].

NIV failure has been defined as the need for endotracheal intubation (ETI) or death [2]. Its rate greatly varies between 5 and $60 \%$, depending on numerous factors, including the cause of ARF [3,4]. Unsuccessful NIV was found to be independently associated with death, especially in patients with de novo ARF [5]. This

\footnotetext{
* Correspondence: stefanava@gmail.com

${ }^{3}$ Department of Specialistic, Diagnostic and Experimental Medicine (DIMES),

Respiratory and Critical Care, University of Bologna, Sant'Orsola Malpighi

Hospital building \#15, Alma Mater Studiorum, via Massarenti n.15,

Bologna 40185, Italy

Full list of author information is available at the end of the article
}

may indicate the need for caution with regard to the application of NIV and for close monitoring to switch promptly to ETI when necessary.

Several investigators have tried to assess the best predictors of NIV failure [6-12]. However, to the best of our knowledge, despite the rather extensive literature in the NIV field, there is only one paper, published 10 years ago, summarizing the evidence for the risk factors for NIV failure, and no studies of the timing of the failure [13]. Based on data from randomized controlled trials (RCTs), three temporal moments were identified: 1$)$ immediate failure (within minutes to $<1 \mathrm{~h}$ ), 2) early failure (1 to $48 \mathrm{~h}$ ), and 3) late failure (after $48 \mathrm{~h}$ ) (Figure 1) [6-12]. The purpose of this narrative review is to illustrate the main patientrelated predictors or risks factors of immediate, early, and late failure. We also discuss possible remedies to avoid ETI and nonpatient-related risk factors. 


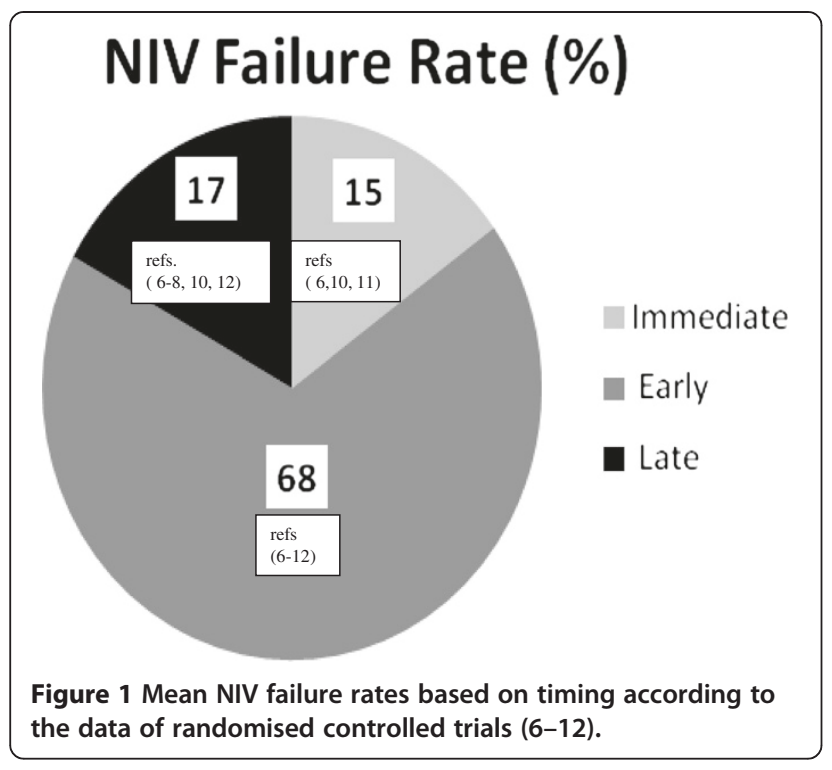

Patient related risk factors Immediate NIV failure

Immediate NIV failure refers to failure within minutes and not beyond the first hour. Excluding patients with contraindications for NIV use (Table 1) [4], about 15\% of

Table 1 Indications and contraindications for NIV in acute care $[4,16,17,35]$

\section{Indications:}

A- Gas exchange:

- Acute or acute on chronic ventilator failure (best indication), $\mathrm{PaCO}_{2}>45 \mathrm{mmHg}$

- $\mathrm{Ph}<7.35$

- Hypoxemia (use with caution), $\mathrm{PaO}_{2} / \mathrm{FIO}_{2}$ ratio $<200$

\section{B- Bedside observations:}

- Increased dyspnea- moderate to severe

- Tachypnoea (24 breaths per minute in obstructive, $>30$ per minute in restrictive)

- Signs of increased work of breathing, accessory muscle use, and abdominal paradox

Absolute contraindications:

- Cardiac or respiratory arrest

- Unable to fit mask

\section{Relative contraindications:}

- Non-respiratory organ failure (severe encephalopathy with GCS $<10$, severe upper gastrointestinal bleeding, hemodynamic instability or unstable cardiac arrthythmia)

- Inability to cooperate/protect the airway

- Inability to clear respiratory secretions

- High risk of aspiration

- Recent facial surgery, trauma, or deformity

- Upper airway obstruction

NIV: Noninvasive ventilation, GCS: Glasgow coma scale. all NIV failures were defined as "immediate" in RCTs, irrespective of the underlying causes of ARF $[6,10,11]$. Predictors of failure in this period have never been systematically analyzed. The causes of NIV failure and possible remedies are reviewed below (Table 2).

Weak cough reflex and/or excessive secretions NIV does not allow direct access to the airways. A weak cough reflex leading to inefficient clearance of excessive secretions from airways is a common cause of immediate NIV failure $[14,15]$. The inability to spontaneously remove secretions is considered a relative contraindication for NIV, especially in patients with impaired consciousness and depressed cough $[16,17]$. Some data indicate that specific "manual" or "mechanical" physiotherapeutic techniques may improve mucociliary clearance during NIV and that NIV can still be used in those circumstances $[18,19]$. Intrapulmonary percussive ventilation (IPV) is a technique that delivers small bursts of high-flow respiratory gas at high rates for mobilization of secretions [20]. Two clinical studies demonstrated that IPV used before or in combination with NIV may reduce the risk of ETI in COPD patients with difficulties removing secretions [19,21]. Early fiberoptic bronchoscopy is another potential intervention that can be used to minimize the burden of respiratory secretions. In a matched case-control study, early suction of secretions performed during NIV was shown to be feasible and safe [22]. However, in a recent prospective multicenter study, ventilatory support needed to be increased after fiberoptic bronchocopy in 35\% of patients with hypoxemic respiratory failure [23].

In conclusion, for patients with a weak cough reflex or excessive secretions, cautious secretion management during NIV use might be advisable before NIV is declared as failed $[4,24]$.

Hypercapnic encephalopathy and coma Hypercapnic encephalopathy (HES) is often considered a cause of immediate NIV failure because of poor compliance due to confusion and/or agitation. Additionally, it is viewed as a relative contraindication because of the increased risk of aspiration [16].

A number of studies clearly demonstrated that cautious application of NIV can be attempted in patients with HES by an experienced team to achieve a fast reduction of $\mathrm{PaCO}_{2}$ and to re-institute the conditions for a successful NIV attempt [25,26]. The risk of aspiration has been shown to be minimized by the rapid improvement of neurological status under NIV and NIV failure rates were reported to be comparable among patients with and without HES [25]. The use of a relatively high back-up rate and/or pressure control ventilation may also help to "capture" the patient better [26]. Another 
Table 2 The risk factors and suggestions for the management of NIV failure based on timing

\section{Time \\ Immediate 1. Weak cough reflex and/or excessive secretions}

2. Hypercapnic encephalopathy and coma

3. Intolerance and psychomotor agitation

4. "Fighting with the machine": Patient-ventilator asynchrony

Early Hypoxemic

ARF

1. Baseline $A B G$ and inability to correct gas exchange $(P / F<150)^{*}$

2. Baseline severity scores (SAPS $\|>35)^{*}$

3. The presence of ARDS/pneumonia/sepsis/multiorgan failure (OR: 4-28)*

4. Increased respiratory rate (>25 breaths/min)*

5. Miscellaneous: Delay between admission and NIV use, Number of fiberoptic bronchoscopes performed, Duration of NIV use, Increase in radiographic infiltrates within the first 24 hours, Causal diagnosis (as 'de novo')

Hypercapnic 1. Baseline ABG and inability to correct gas exchange $(\mathrm{pH}<7.25)^{*}$

ARF

2. Increased severity of disease

3. Increased respiratory rate ( $>35$ breaths/min, OR for baseline and after 2 hours of NIV: 2.66 and 4.95$)^{*}$

4. Mixed indices:

GCS, APACHE II score, respiratory rate and $\mathrm{pH}$

Respiratory rate, random glucose level and APACHE ॥

Anemia and World Health Organization Performance Status (WHO-PS)

5. Miscellaneous: Poor nutritional status, Increased heart rate, Higher baseline Creactive protein/white blood cell count, Lower serum potassium, Airway colonization by non-fermenting gram-negative bacilli

Late

1. Sleep disturbance

2. Functional limitation

3. Possible initial improvement in $\mathrm{pH}$

4. Hyperglycemia

Suggested interventions

1a. Manual or mechanic chest physiotherapeutic techniques; b. Early

fiberoptic bronchoscopy.

2a. Set a back-up rate $\sim 15 \mathrm{~b} / \mathrm{min}$ and/or use PCV; b. Decrease the $\mathrm{F}_{\mathrm{O}} \mathrm{O} 2$ level.

3. Judicious sedation

4a. Closely monitor ventilator waveforms; b. Judicious sedation;

c. Use a ventilator with an NIV platform; $d$. Change ventilatory parameters;

e. Minimize air-leaks.

References

[14-24]

$[16,25-27]$

[14,28-32]

$[33,34]$

$[4]([36,38,39,42 *])$

$\left[1,5,36^{*}, 37^{*}, 39,43,49^{*}-51\right]$

$\left[36^{*}, 40,41,49,50,52^{*}-54\right]$

$[51 *, 53,55 *, 56]$

$[1,36,43,51,53,57]$

$\left[3^{*}, 6,12,14,58-60,62,63\right]$

$[3,12,14,15,59,62,64]$

$\left[3^{*}, 6,15,58,59\right]$

$[63,68,69]$

1a. Improve quality of sleep; b. Avoid excessive noise and light in the unit

$[70]$

3a. Close and continuous monitoring of vital parameters; $b$. Repeat

frequent ABGs during NIV, even when gas exchange reach a satisfactory

4. Check glucose levels

Odd Ratio (OR) or absolute "predictive" values for some parameters are reported from the studies quoted in the references and marked with * from other references. 
key factor in patients with HES is the rebound effect of high-fractionated oxygen $\left(\mathrm{F}_{\mathrm{i}} \mathrm{O}_{2}\right)$ on the $\mathrm{PaCO}_{2}$ and $\mathrm{pH}$, known as the "Haldane effect" [27]. This effect can be prevented by a simple intervention: decreasing the $\mathrm{F}_{\mathrm{i}} \mathrm{O}_{2}$ level.

Intolerance and psychomotor agitation Patient tolerance has been shown to be critical for NIV success, especially in the first few minutes while the patient adapts to this "new mode" of breathing [14]. Interfaces can lead to intolerance. However, the role of these interfaces will be discussed later because they are not directly related to the patient.

The use of judicious sedation may be valuable to achieve a sedation level that keeps the patient awake, easily arousable, and comfortable. Ideal sedatives should be short acting and have no significant effects on respiratory drive and hemodynamics [28-30]. Remifentanil, an opioid with an elimination half-life less than $10 \mathrm{~min}$, provides rapid onset of sedation and easy arousal. Two pilot studies performed in patients who initially failed an NIV trial due to intolerance and therefore met ETI criteria showed that the administration of remifentanil removed the need for intubation in most of the patients $[31,32]$. A pilot study showed that a safe and satisfactory level of sedation during NIV could be achieved with dexmedetomidine, an alpha-2-adrenoceptor agonist [30]. Compared to midazolam, dexmedetomidine led to a more desired level of awaking sedation, and it shortened the duration of mechanical ventilation and ICU stays in patients with acute cardiogenic pulmonary edema.

Although sedation has been suggested as a remedy for intolerance, the "real life experience" shows that, only a minority of physicians use sedation and analgesia during NIV as a routine and it is usually without a specific protocol [29].

It has to be kept in mind that oversedation during NIV can be potentially dangerous. Thus, close monitoring with evaluation of arterial blood gas (ABG), cardiopulmonary and ventilator parameters, adverse events, and the level of sedation is mandatory.

Fighting with the machine: patient-ventilator asynchrony Asynchrony has rarely been cited as a direct cause of NIV immediate failure. However, indirect evidence suggests that this may be the case [33]. Asynchrony can easily be detected by a physical examination (e.g., number of spontaneous breaths vs. ventilator-delivered breaths, accessory muscle use) of the patient and symptoms (e.g., dyspnea). Two main causes of asynchrony are a high level of ventilator support and an increased number of leaks.

A number of strategies can be implemented to avoid "gross asynchronies," such as optimization of ventilator settings using the screen ventilator waveforms, adjusting trigger sensitivity, increasing positive end-expiratory pressure, minimizing leaks, using different modes or more sophisticated ventilators [33]. New modes of ventilation, such as neutrally adjusted ventilator assist, have been documented to reduce asynchrony [34].

\section{Early NIV failure}

Nearly $65 \%$ of NIV failures occur within $1-48$ h of NIV use (Figure 1), [6-8,10,12]. This time interval has received more attention in assessments of predictors of failure. As most studies have focused on NIV use in either hypercapnic or pure hypoxic ARF, these two conditions will be considered separately. Rather than giving possible solutions, as in the previous section (Section 1), we will discuss the most reasonable clinical decision to be applied.

Hypoxemic respiratory failure Hypoxemic ARF can be the end point of several pathologies, including pneumonia, acute respiratory distress syndrome (ARDS), and cardiogenic pulmonary edema (CPE), each of which acts through different mechanisms (e.g., shunting, ventilation/perfusion mismatch, or diffusion limitation). Robust RCTs of the utilization of NIV for hypoxemic ARF are scarce, explaining the absence of specific recommendations in evidence-based guidelines [35]. Therefore, it is difficult to make general statements about risk factors and predictive factors of NIV failure covering all causes of hypoxemic ARF (Table 2).

Baseline ABG and inability to correct gas exchange Oxygenation impairment, as shown by a decreased ratio of $\mathrm{PaO}_{2}$ to $\mathrm{FiO}_{2}$ (P/F ratio), is one of the most welldocumented risk factors and predictors of NIV failure. The outcomes of the patients are probably more dependent on the underlying cause, rather than on the baseline severity of the hypoxemia itself. A prospective multicenter study investigating variables predictive of NIV failure in 354 patients with hypoxemic ARF reported a higher ETI rate in patients with ARDS (51\%) and community-acquired pneumonia (CAP) $(50 \%)$ than in patients with pulmonary contusion (18\%) and CPE (10\%) [36]. In this study, most ETIs occurred due to the inability of NIV to correct gas exchange (62\%). Although the ABG values at study entry had no predictive value, severe hypoxemia $(\mathrm{P} / \mathrm{F} \leq 146)$ after $1 \mathrm{~h}$ of NIV treatment was reported to be an independent predictor of NIV failure according to multivariate analysis [36].

\section{ARDS and CAP}

In a group of patients with ARDS, the inability to improve the $\mathrm{P} / \mathrm{F}$ ratio after $1 \mathrm{~h}$ of NIV use $(\mathrm{P} / \mathrm{F} \leq 175)$ was shown to be an independent predictor of NIV failure [37]. 
However, in another prospective observational study, the baseline $\mathrm{P} / \mathrm{F}$ ratio $(<120)$ was shown to be the only factor associated with NIV failure [38]. Likewise, a low $\mathrm{P} / \mathrm{F}$ ratio at admission was found to be a risk factor for immune-suppressed patients with pneumonia and extrapulmonary sepsis and for patients with $\mathrm{H}_{1} \mathrm{~N}_{1}$ pneumonia $[39,40]$ and acute lung injury (ALI) (in this latter group with an odd ratio $=1.03$, per unit decrease in $\mathrm{PaO}_{2} / \mathrm{FiO}_{2}$ ) for NIV failure [41]. P/F ratios at both baseline (around 115) and after $1 \mathrm{~h}$ of NIV use (around 140) were indicated as independent predictors of NIV failure in patients with severe CAP [42].

Metabolic values on ABGs, other than oxygen levels, should also be carefully assessed. The serum bicarbonate level, as well as the P/F ratio, $1 \mathrm{~h}$ after NIV onset was an independent predictor of NIV failure in patients with CAP and severe ARDS [43]. Metabolic acidosis was reported to be a significant predictor of unsuccessful NIV in patients with ALI [41].

\section{Cardiogenic pulmonary edema (CPE)}

Generally, the rate of NIV failure is very low in patients with CPE. In a study of 2430 patients, the NIV success rate was $96 \%$, and oxygen saturation was lower in the failure group [44]. Masip et al. demonstrated that acute myocardial infarction, a low $\mathrm{pH}$ $(<7.25)$, a low ejection fraction $(<30 \%)$, hypercapnia, and low systolic blood pressure $(<140 \mathrm{mmHg})$ were independent predictors for ETI [45]. A pH level of 7.03 was shown to be a cut-off level to predict NIV success, with the highest sensitivity and specificity observed in patients with CPE [46].

To summarize, the severity of hypoxemia and acidosis and their initial responses to NIV are strong predictors of NIV outcomes. NIV should be performed very cautiously, especially in patients with a $\mathrm{P} / \mathrm{F}<150$ and diagnosed as ARDS or CAP. Vital signs and ABGs should be monitored very closely, starting even before the "classical" $60 \mathrm{~min}$ frame. The initial amelioration of ABGs does not imply that NIV will be successful, and strict monitoring should be continued in the following days [36-41].

\section{Baseline severity scores}

Although some previous research failed to indicate any relationship between baseline severity scores (reflecting the severity of the disease) and NIV outcomes $[47,48]$, most recent trials clearly confirmed this relationship $[1,5,36,37,49]$.

Higher SOFA, APACHE II, and/or SAPS II scores were related with NIV failure in studies performed in either all patients with ARF or patients with hypoxemic ARF postoperatively or hypoxemic ARF due to sepsis, pneumonia or hematological malignancies [1,5,39,43,49-51]. An
SAPS II score $\geq 34$ was identified as an independent risk factor for NIV failure in hypoxemic ARF [36,37].

To avoid harmful delays in ETI, these indexes should always be evaluated in patients using NIV with these disorders. It should be kept in mind that an SAPS II score in the middle 30 s is associated with a very high risk of failure.

\section{Presence of ARDS/pneumonia/sepsis/multiorgan failure}

As stated earlier (2.1.1), underlying disease is the major risk factor for NIV failure. De novo ARF was shown to be associated with NIV failure and subsequent ETI in all ARF patients administered NIV $[1,5]$. In an observational study, the presence of ARDS or CAP was identified as a risk factor for NIV failure $(\mathrm{OR}=3.75)$ [36]. In an RCT, ARDS was significantly associated with ETI $(\mathrm{OR}=28.5)$ [52]. These findings were also confirmed in patients with pulmonary infiltrates due to hematological malignancy or CAP in postoperative ARF $[49,50,53]$.

Multiorgan failure and hemodynamic instability have been documented as risk factors of NIV failure in immunosuppressed patients with hypoxemic ARF [40,53]. In an observational study, $35 \%$ of patients with ALI requiring NIV were diagnosed with septic shock, and NIV failed in all the patients [41].

At present, we cannot recommend the use of NIV in patients with moderate to severe hypoxia $(\mathrm{P} / \mathrm{F}=<200)$ diagnosed with ARDS or CAP or in patients with septic shock, in agreement with the statement of the surviving sepsis campaign [54].

\section{Increased respiratory rate}

An increased respiratory rate $1 \mathrm{~h}$ after NIV is a frequently reported risk factor for NIV failure in patients with ARF postoperatively or ARF due to hematological malignancies or ALI $[51,53,55]$. These studies suggested that an average respiratory rate $>25$ breaths $/ \mathrm{min}$ on NIV is a predictor of failure because it is a surrogate of increased work of breathing. The so-called rapid shallow breathing index $>105$ (i.e., the ratio between the breathing frequency/tidal volume) under NIV has also been demonstrated to be independently associated with ETI (multivariate OR: 3.70) [56].

\section{Miscellaneous risk factors of NIV failure}

Other risk factors for NIV failure in hypoxemic ARF are the delay between admission and NIV use, number of fiberoptic bronchoscopies performed, duration of NIV use, increase in radiographic infiltrates within the first $24 \mathrm{~h}$, and causal diagnosis (as de novo) of ARF $[1,43,51,53]$. Age has been demonstrated to be a risk factor (with a low OR) only in a minority of studies $[1,36,57]$. 


\section{Hypercapnic respiratory failure}

The utilization of NIV in hypercapnic ARF, as well as the risk factors for its failure, has probably been more intensively studied compared to its use in hypoxic ARF (Table 2). Although hypercapnic ARF covers ARF due to neurological disorders (such as neuromuscular disorders) or other acute or chronic lung disorders (such as restrictive lung disease), most of the studies done in this field have involved patients with COPD exacerbations $[3,58]$.

\section{Baseline ABG and inability to correct gas exchange}

The $\mathrm{pH}$ level, which is an indicator of the severity of hypercapnia, has been reported to be a critical factor in determining the success of NIV. Although some reports failed to show any relationship between baseline ABGs and the success of NIV [15,48], a large body of evidence clearly indicated that a lower baseline $\mathrm{pH}$ is a risk factor for NIV failure in COPD patients [3,6,12,14,58-60]. In nearly $50-60 \%$ of patients with a baseline $\mathrm{pH}$ of $<7.25$, NIV was unsuccessful $[6,12]$. A subgroup analysis of COPD patients with mild to moderate acidosis revealed that NIV improved patient outcomes only if the baseline $\mathrm{pH}$ was $\geq 7.30$ [58].

In addition to baseline levels, $\mathrm{pH}$ values $1 \mathrm{~h}$ after the application of NIV were shown to be strong predictors of the success of NIV, with high sensitivity and good specificity ( $93 \%$ and $82 \%$, respectively) [59]. In a study of more than 1000 COPD patients, Confalonieri et al. pointed out that a $\mathrm{pH}<7.25$ after $1 \mathrm{~h}$ of NIV use was associated with an increased risk of failure and that the risk of failure was even greater than when the $\mathrm{pH}$ levels were $<7.25$ at admission [3].

For the above mentioned reasons, we do not recommend routine use of NIV in patients with a $\mathrm{pH}<7.25$ outside a "protected" environment [16,17]. However, recently, NIV has been offered as an effective treatment option for patients with severe acidosis due to COPD, even if performed in a respiratory ward [61]. In this study, NIV improved $\mathrm{pH}$ and $\mathrm{PaCO}_{2}$ to the same extent in two groups of patients with mild acidosis and severe acidosis $(\mathrm{pH}<7.25)$ and overall survival rate was also comparable. However, the study's findings should be interpreted cautiously. RCTs are required to confirm that NIV can be safely applied in patients with severe acidosis outside step-down units or ICUs.

Risk factors and predictors of NIV failure were also assessed in non-COPD patients with hypercapnic ARF. A low $\mathrm{P} / \mathrm{F}$ ratio (on average $<200$ ), higher $\mathrm{PaCO}_{2}$, and a lower $\mathrm{pH}$ after $1 \mathrm{~h}$ of NIV were reported as independent predictors of NIV failure in a subset of heterogeneous patients, including those with bronchiectasis and pulmonary tuberculosis sequelae $[62,63]$.

\section{Increased severity of disease}

The relationship between NIV failure and the severity scores, including APACHE II and SAPS II, has been documented in a number of reports. Several researchers found an association $[3,12,14,15,59,62,64]$, whereas others failed to find any association [5,48]. Interestingly, in a study of more than 500 patients, although a high SAPS II was a strong indicator of NIV failure and death in hypoxic ARF, this was not the case for hypercapnic ARF (OR = 3.05 vs. 1.17 , respectively) [5]. Therefore, in this latter population, the presence of acute or chronic comorbidities may be stronger risk factors for NIV failure than the severity indices [65].

\section{Increased respiratory rate}

An initial high respiratory rate and its reduction after $1 \mathrm{~h}$ of NIV have been shown to be associated with successful NIV outcomes in COPD patients $[6,15,58,59]$. A respiratory rate of 30-34 and $\geq 35$ breaths/min at admission were demonstrated to lead to NIV failure, with an OR of 1.83 and 2.66, respectively, whereas the ratios increased to 2.67 and 4.95 , respectively, for the same breathing frequency after $2 \mathrm{~h}$ of NIV [3].

\section{Mixed indices}

Some investigators have suggested using mixed indices to improve the probability of the prediction of NIV failure. A risk stratification chart of NIV failure demonstrated that COPD patients with a Glasgow Coma Scale $(\mathrm{GCS})<11$, an APACHE II score $\geq 29$, a respiratory rate $\geq 30$ breaths $/ \mathrm{min}$, and a $\mathrm{pH}<7.25$ at admission had a risk of failure $>70 \%$ [3]. The risk increased up to $95 \%$ for the same parameters after $2 \mathrm{~h}$ of NIV therapy [3]. The prediction of NIV success was $97 \%$ with a combination of a respiratory rate $<30 \mathrm{bpm}$ and glucose $<7 \mathrm{mmol} / \mathrm{L}$ [66]. Anemia and a World Health Organization performance status (WHO-Performance Status) score $\geq 3$ were also shown to be significant predictors of mortality and NIV failure [67].

Thus far, the risk chart developed by Confalonieri et al. [3] is probably the best mixed index for predicting NIV outcomes with reasonable accuracy.

\section{Miscellaneous}

Poor nutritional status (i.e., a low BMI), a high white blood cell count, low serum potassium, and an increased heart rate are additional risk factors for NIV failure $[63,68]$. Two additional issues may merit specific consideration. Old age has never been shown to be a "negative" variable in determining NIV outcomes, and older patients with hypercapnic ARF may respond even better than younger ones to NIV [69]. The combination of ARF and pneumonia is probably one of the strongest determinants of NIV failure [59], 
but this has never been extensively studied, as most of the RCTs excluded a priori these patients.

\section{Late NIV failure}

Although the definition of late NIV failure has not been standardized; it is usually defined as failure that occurs $48 \mathrm{~h}$ after initiation of NIV, following an initial successful response. Late NIV failure has received less attention and has been studied mainly in hypercapnic ARF. $[2,6-8,10,12,64,70]$. Actually, it occurs in a considerable subset of patients (about 15\% of NIV failures) (Figure 1).

The occurrence of late failure in COPD patients admitted with hypercapnic ARF to ICUs when NIV was used $>24$ h was found to be associated with functional limitation before admission, the presence of hyperglycemia, and a lower $\mathrm{pH}$ at admission [2]. $\mathrm{PaCO}_{2}$ and $\mathrm{pH}$ values improved gradually and similarly within the first $24 \mathrm{~h}$ in both success and late failure groups [2]. This is of particular importance because initial good responses to NIV may decrease attention and monitoring by clinicians in the following hours $[2,64]$. During a hospital stay, pneumonia was more frequently observed as a complication in a late failure group compared to a success group ( $12.9 \%$ vs. $0 \%)$ [2]. It is logical that the occurrence of infectious complications and/or multiple organ failure may result in late NIV failure, but such risk factors have never been addressed in a trial. The mortality of a late failure group was extremely high compared to a successful group in another study (68 vs. 0\%) [2]. In a recent study, sleep disturbance (classified as an abnormal electroencephalographic pattern, greater circadian sleep-cycle disruption, and less nocturnal rapid eye movement sleep) and increased delirium during an ICU stay were also associated with late NIV failure in hypercapnic patients [70].

NIV patients should be continuously monitored (including their sleep patterns and state of delirium), even if their initial clinical and ABG responses are good because late NIV failure can lead to high mortality.

\section{Non-patient related risk factors}

The timing of the application of NIV is a critical factor. A longer delay between admission and NIV use was shown to be an independent risk factor for NIV failure in patients with hematological malignancy and hypoxemic ARF, probably due to the progression of the underlying disease [53]. Therefore, early use of NIV is recommended. It is also critical not to unduly delay the decision to intubate a patient with failed NIV, because the risk of unanticipated respiratory or cardiac arrest could lead to increased morbidity and mortality.

The location of the NIV therapy is another important determinant in the success of NIV. There are advantages and disadvantages of different locations (including ICUs, step-down units, wards, and emergency care) for
NIV application, and these have been discussed in detail elsewhere [71]. The decision about where to perform NIV should be based on matching the capabilities of the units and teams with the patient's clinical severity and the need for monitoring.

The experience and the skills of the staff are other key components of NIV success. One study suggested that training in NIV implementation is an important factor in reducing nasocomial infections and improving survival in critically ill patients with COPD and ACPE [72]. Another found that improvements in skill with time may explain the decreased time spent by nurses at the bedside of patients today compared to data reported 20 years ago [73].

The choice of ventilator is crucial in NIV success in the acute setting, with inadequate equipment leading to poor tolerance and excessive air leaks being documented as a barrier to NIV use [74]. On average, dedicated NIV platforms perform better than ICU ventilators using the NIV algorithm [75]. In particular, the synchrony between the machine and the patient is better with dedicated NIV platforms [75].

Although much attention has been paid to the development of new interfaces to increase tolerance and patient comfort, mask intolerance remains a major cause of NIV failure [32]. An oronasal mask is generally the most commonly preferred one in ARF, followed by nasal masks, helmets, and mouthpieces. There are various advantages and disadvantages of these interfaces. In the case of poor tolerance, a wise choice may be the application of the so-called "rotating" strategy proposed by Hilbert et al. [76].

Some authors concluded that humidification during NIV for ARF is controversial and that the effect of humidification on the success of NIV is unclear [77]. However, heated humidification is recommended to minimize the work of breathing and to maximize $\mathrm{PaCO}_{2}$ clearance, with less dead space than ventilators with heat and moisture exchangers.

\section{Conclusions}

Risk factors and predictors of NIV failure are numerous. They differ between hypercapnic and hypoxemic patients and according to the timing of the failure. Every physician dealing with NIV should be aware of these risk factors and closely monitor each patient for their presence or development to achieve a good response and to improve the prognosis. If a patient fails to improve sufficiently, prompt ETI should be performed without a delay because there is an increased risk of morbidity and mortality with ETI after failed NIV. A satisfactory initial NIV attempt is not always a marker of a good outcome. Late NIV failure may occur in up to $15 \%$ of patients in whom the initial NIV attempt was satisfactory. 


\section{Competing interests}

The authors declare that they have no competing interests.

\section{Authors' contributions}

$\mathrm{EO}, \mathrm{AOU}$ and SN designed the study. EO and AOU collected the data involved in drafting the manuscript. SN revised the manuscript critically for significant intellectual content. All of the authors have given final approval of the version to be published.

\section{Acknowledgements}

We thank to Scribendi INC. for the revision of the English manuscript.

\section{Author details}

'Cukurova University Faculty of Medicine Department of Pulmonary Disease, Adana, Turkey. ${ }^{2}$ Baskent University Faculty of Medicine Department of Pulmonary Disease, İstanbul, Turkey. ${ }^{3}$ Department of Specialistic, Diagnostic and Experimental Medicine (DIMES), Respiratory and Critical Care, University of Bologna, Sant'Orsola Malpighi Hospital building \#15, Alma Mater Studiorum, via Massarenti n.15, Bologna 40185, Italy.

Received: 10 October 2013 Accepted: 29 January 2014

Published: 13 February 2014

\section{References}

1. Demoule A, Girou E, Richard JC, Taille S, Brochard L: Increased use of noninvasive ventilation in French intensive care units. Intensive Care Med 2006, 32:1747-1755.

2. Moretti M, Cilione C, Tampieri A, Fracchia C, Marchioni A, Nava S: Incidence and causes of non-invasive mechanical ventilation failure after initial success. Thorax 2000, 55:819-825.

3. Confalonieri M, Garuti G, Cattaruzza MS, Osborn JF, Antonelli M, Conti G, Kodric M, Resta O, Marchese S, Gregoretti C, Rossi A: A chart of failure risk for noninvasive ventilation in patients with COPD exacerbation. Eur Respir J 2005, 25:348-355.

4. Nava S, Hill N: Non-invasive ventilation in acute respiratory failure. Lancet 2009, 374:250-259.

5. Demoule A, Girou E, Richard JC, Taille S, Brochard L: Benefits and risks of success or failure of noninvasive ventilation. Intensive Care Med 2006, 32:1756-1765.

6. Brochard L, Mancebo J, Wysocki M, Lofaso F, Conti G, Rauss A, Simonneau G, Benito S, Gasparetto A, Lemaire F, et al: Noninvasive ventilation for acute exacerbations of chronic obstructive pulmonary disease. N Engl J Med 1995, 333:817-822.

7. Martin TJ, Hovis JD, Costantino JP, Bierman MI, Donahoe MP, Rogers RM, Kreit JW, Sciurba FC, Stiller RA, Sanders MH: A randomized, prospective evaluation of noninvasive ventilation for acute respiratory failure. Am J Respir Crit Care Med 2000, 161:807-813.

8. Antonelli M, Conti G, Bufi M, Costa MG, Lappa A, Rocco M, Gasparetto A, Meduri GU: Noninvasive ventilation for treatment of acute respiratory failure in patients undergoing solid organ transplantation: a randomized trial. JAMA 2000, 283:235-241.

9. Celikel T, Sungur M, Ceyhan B, Karakurt S: Comparison of noninvasive positive pressure ventilation with standard medical therapy in hypercapnic acute respiratory failure. Chest 1998, 114:1636-1642.

10. Confalonieri M, Potena A, Carbone G, Porta RD, Tolley EA, Umberto Meduri G: Acute respiratory failure in patients with severe community-acquired pneumonia. A prospective randomized evaluation of noninvasive ventilation. Am J Respir Crit Care Med 1999, 160:1585-1591.

11. Keenan SP, Powers CE, McCormack DG: Noninvasive positive-pressure ventilation in patients with milder chronic obstructive pulmonary disease exacerbations: a randomized controlled trial. Respir Care 2005, 50:610-616.

12. Conti G, Antonelli M, Navalesi P, Rocco M, Bufi M, Spadetta G, Meduri GU: Noninvasive vs. conventional mechanical ventilation in patients with chronic obstructive pulmonary disease after failure of medical treatment in the ward: a randomized trial. Intensive Care Med 2002, 28:1701-1707.

13. Nava S, Ceriana P: Causes of failure of noninvasive mechanical ventilation. Respir Care 2004, 49:295-303.

14. Carlucci A, Richard JC, Wysocki M, Lepage E, Brochard L: Noninvasive versus conventional mechanical ventilation. An epidemiologic survey. Am J Respir Crit Care Med 2001, 163:874-880.
15. Soo Hoo GW, Santiago S, Williams AJ: Nasal mechanical ventilation for hypercapnic respiratory failure in chronic obstructive pulmonary disease: determinants of success and failure. Crit Care Med 1994, 22:1253-1261.

16. nternational Consensus Conferences: Intensive Care Medicine: noninvasive positive pressure ventilation in acute Respiratory failure. Am J Respir Crit Care Med 2001, 163:283-291.

17. British Thoracic Society Standards of Care Committee: Non-invasive ventilation in acute respiratory failure. Thorax 2002, 57:192-211.

18. Bellone A, Spagnolatti L, Massobrio M, Bellei E, Vinciguerra R, Barbieri A, lori $E$, Bendinelli $S$, Nava $S$ : Short-term effects of expiration under positive pressure in patients with acute exacerbation of chronic obstructive pulmonary disease and mild acidosis requiring non-invasive positive pressure ventilation. Intensive Care Med 2002, 28:581-585.

19. Vargas F, Bui HN, Boyer A, Salmi LR, Gbikpi-Benissan G, Guenard H, Gruson D, Hilbert G: Intrapulmonary percussive ventilation in acute exacerbations of COPD patients with mild respiratory acidosis: a randomized controlled trial [ISRCTN17802078]. Crit Care 2005, 9:R382-R389.

20. Nava S, Barbarito N, Piaggi G, De Mattia E, Cirio S: Physiological response to intrapulmonary percussive ventilation in stable COPD patients. Respir Med 2006, 100:1526-1533.

21. Antonaglia V, Lucangelo U, Zin WA, Peratoner A, De Simoni L, Capitanio G, Pascotto S, Gullo A: Intrapulmonary percussive ventilation improves the outcome of patients with acute exacerbation of chronic obstructive pulmonary disease using a helmet. Crit Care Med 2006, 34:2940-2945.

22. Scala R, Naldi M, Maccari U: Early fiberoptic bronchoscopy during non-invasive ventilation in patients with decompensated chronic obstructive pulmonary disease due to community-acquired-pneumonia. Crit Care 2010, 14:R80.

23. Cracco C, Fartoukh M, Prodanovic H, Azoulay E, Chenivesse C, Lorut C, Beduneau G, Bui HN, Taille C, Brochard L, Demoule A, Maitre B: Safety of performing fiberoptic bronchoscopy in critically ill hypoxemic patients with acute respiratory failure. Intensive Care Med 2013, 39:45-52.

24. Ambrosino N, Vagheggini G: Noninvasive positive pressure ventilation in the acute care setting: where are we? Eur Respir J 2008, 31:874-886.

25. Scala R, Nava S, Conti G, Antonelli M, Naldi M, Archinucci I, Coniglio G, Hill NS: Noninvasive versus conventional ventilation to treat hypercapnic encephalopathy in chronic obstructive pulmonary disease. Intensive Care Med 2007, 33:2101-2108.

26. Gonzalez Dıaz G, Carrillo Alcaraz A, Pardo Talavera JC, Jara Perez P, Esquinas Rodriguez A, Garca Cordoba F, Hill NS: Noninvasive positive-pressure ventilation to treat hypercapnic coma secondary to respiratory failure. Chest 2005, 127:952-960.

27. Becker HF, Polo O, McNamara SG, Berthon-Jones M, Sullivan CE: Effect of different levels of hyperoxia on breathing in healthy subjects. $J$ Appl Physiol 1996, 81:1683-1690.

28. Hilbert G, Clouzeau B, Nam Bui H, Vargas F: Sedation during non-invasive ventilation. Minerva Anestesiol 2012, 78:842-846.

29. Devlin JW, Nava S, Fong JJ, Bahhady I, Hill NS: Survey of sedation practices during noninvasive positive-pressure ventilation to treat acute respiratory failure. Crit Care Med 2007, 35:2298-2302.

30. Huang Z, Chen YS, Yang ZL, Liu JY: Dexmedetomidine versus midazolam for the sedation of patients with non-invasive ventilation failure. Intern Med 2012, 51:2299-2305.

31. Constantin JM, Schneider E, Cayot-Constantin S, Guerin R, Bannier F, Futier E, Bazin JE: Remifentanil-based sedation to treat noninvasive ventilation failure: a preliminary study. Intensive Care Med 2007, 33:82-87.

32. Rocco M, Conti G, Alessandri E, Morelli A, Spadetta G, Laderchi A, Di Santo C, Francavilla S, Pietropaoli P: Rescue treatment for noninvasive ventilation failure due to interface intolerance with remifentanil analgosedation: a pilot study. Intensive Care Med 2010, 36:2060-2065.

33. Di Marco F, Centanni S, Bellone A, Messinesi G, Pesci A, Scala R, Perren A, Nava $S$ : Optimization of ventilator setting by flow and pressure waveforms analysis during noninvasive ventilation for acute exacerbations of COPD: a multicentric randomized controlled trial. Crit Care 2011, 15:R283.

34. Bertrand PM, Futier E, Coisel Y, Matecki S, Jaber S, Constantin JM: Neurally adjusted ventilatory assist vs pressure support ventilation for noninvasive ventilation during acute respiratory failure: a crossover physiologic study. Chest 2012, 143:30-36.

35. Keenan SP, Sinuff T, Burns KE, Muscedere J, Kutsogiannis J, Mehta S, Cook DJ, Ayas N, Adhikari NK, Hand L, Scales DC, Pagnotta R, Lazosky L, Rocker G, Dial S, Laupland K, Sanders K, Dodek P: Clinical practice guidelines for the use of 
noninvasive positive-pressure ventilation and noninvasive continuous positive airway pressure in the acute care setting. CMAJ 2011, 183:E195-E214.

36. Antonelli M, Conti G, Moro ML, Esquinas A, Gonzalez-Diaz G, Confalonieri M, Pelaia P, Principi T, Gregoretti C, Beltrame F, Pennisi MA, Arcangeli A, Proietti R, Passariello M, Meduri GU: Predictors of failure of noninvasive positive pressure ventilation in patients with acute hypoxemic respiratory failure: a multi-center study. Intensive Care Med 2001, 27:1718-1728.

37. Antonelli M, Conti G, Esquinas A, Montini L, Maggiore SM, Bello G, Rocco M, Maviglia R, Pennisi MA, Gonzalez-Diaz G, Meduri GU: A multiple-center survey on the use in clinical practice of noninvasive ventilation as a first-line intervention for acute respiratory distress syndrome. Crit Care Med 2007, 35:18-25.

38. Agarwal R, Handa A, Aggarwal AN, Gupta D, Behera D: Outcomes of noninvasive ventilation in acute hypoxemic respiratory failure in a respiratory intensive care unit in north India. Respir Care 2009, 54:1679-1687.

39. Nicolini A, Tonveronachi E, Navalesi P, Antonelli M, Valentini I, Melotti RM, Pigna A, Carrassi A, Righini P, Ferrari Bravo M, Pelosi P, Nicoli F, Cosentini R, Vaschetto R, Faenza S, Nava S: Effectiveness and predictors of success of noninvasive ventilation during $\mathrm{H} 1 \mathrm{~N} 1$ pandemics: a multicenter study. Minerva Anestesiol 2012, 78:1333-1340.

40. Razlaf P, Pabst D, Mohr M, Kessler T, Wiewrodt R, Stelljes M, Reinecke H, Waltenberger J, Berdel WE, Lebiedz P: Non-invasive ventilation in immunosuppressed patients with pneumonia and extrapulmonary sepsis. Respir Med 2012, 106:1509-1516.

41. Rana S, Jenad H, Gay PC, Buck CF, Hubmayr RD, Gajic O: Failure of non-invasive ventilation in patients with acute lung injury: observational cohort study. Crit Care 2006, 10:R79

42. Carron M, Freo U, Zorzi M, Ori C: Predictors of failure of noninvasive ventilation in patients with severe community-acquired pneumonia. J Crit Care 2010, 25:540.e9-14.

43. Carrillo A, Gonzalez-Diaz G, Ferrer M, Martinez-Quintana ME, Lopez-Martinez A, Llamas N, Alcazar M, Torres A: Non-invasive ventilation in communityacquired pneumonia and severe acute respiratory failure. Intensive Care Med 2012, 38:458-466

44. Tallman TA, Peacock WF, Emerman CL, Lopatin M, Blicker JZ, Weber J, Yancy CW: Noninvasive ventilation outcomes in 2,430 acute decompensated heart failure patients: an ADHERE registry analysis. Acad Emerg Med 2008, 15:355-362.

45. Masip J, Paez J, Merino M, Parejo S, Vecilla F, Riera C, Rios A, Sabater J, Ballus J, Padro J: Risk factors for intubation as a guide for noninvasive ventilation in patients with severe acute cardiogenic pulmonary edema. Intensive Care Med 2003, 29:1921-1928.

46. Shirakabe A, Hata N, Yokoyama S, Shinada T, Kobayashi N, Tomita K, Kitamura M, Nozaki A, Tokuyama H, Asai K, Mizuno K: Predicting the success of noninvasive positive pressure ventilation in emergency room for patients with acute heart failure. J Cardio/ 2010, 57:107-114.

47. Meduri GU, Turner RE, Abou-Shala N, Wunderink R, Tolley E: Noninvasive positive pressure ventilation via face mask. First-line intervention in patients with acute hypercapnic and hypoxemic respiratory failure. Chest 1996, 109:179-193.

48. Anton A, Guell R, Gomez J, Serrano J, Castellano A, Carrasco JL, Sanchis J: Predicting the result of noninvasive ventilation in severe acute exacerbations of patients with chronic airflow limitation. Chest 2000 117:828-833.

49. Wallet F, Schoeffler M, Reynaud M, Duperret S, Workineh S, Viale JP: Factors associated with noninvasive ventilation failure in postoperative acute respiratory insufficiency: an observational study. Eur J Anaesthesiol 2010, 27:270-274

50. Gristina GR, Antonelli M, Conti G, Ciarlone A, Rogante S, Rossi C, Bertolini G: Noninvasive versus invasive ventilation for acute respiratory failure in patients with hematologic malignancies: a 5-year multicenter observational survey. Crit Care Med 2011, 39:2232-2239.

51. Riviere S, Monconduit J, Zarka V, Massabie P, Boulet S, Dartevelle P, Stephan $F$ : Failure of noninvasive ventilation after lung surgery: a comprehensive analysis of incidence and possible risk factors. Eur J Cardiothorac Surg 2010, 39:769-776.

52. Ferrer M, Esquinas A, Leon M, Gonzalez G, Alarcon A, Torres A: Noninvasive ventilation in severe hypoxemic respiratory failure: a randomized clinical trial. Am J Respir Crit Care Med 2003, 168:1438-1444.

53. Adda M, Coquet I, Darmon M, Thiery G, Schlemmer B, Azoulay E: Predictors of noninvasive ventilation failure in patients with hematologic malignancy and acute respiratory failure. Crit Care Med 2008, 36:2766-2772.

54. Dellinger RP, Levy MM, Rhodes A, Annane D, Gerlach H, Opal SM, Sevransky JE, Sprung CL, Douglas IS, Jaeschke R, Osborn TM, Nunnally ME, Townsend SR, Reinhart K, Kleinpell RM, Angus DC, Deutschman CS, Machado FR, Rubenfeld GD, Webb SA, Beale RJ, Vincent JL, Moreno R: Surviving sepsis campaign: international guidelines for management of severe sepsis and septic shock. Crit Care Med 2013, 41:580-637.

55. Yoshida Y, Takeda S, Akada S, Hongo T, Tanaka K, Sakamoto A: Factors predicting successful noninvasive ventilation in acute lung injury. $J$ Anesth 2008, 22:201-206.

56. Berg KM, Lang GR, Salciccioli JD, Bak E, Cocchi MN, Gautam S, Donnino MW: The rapid shallow breathing index as a predictor of failure of noninvasive ventilation for patients with acute respiratory failure. Respir Care 2012, 57:1548-1554

57. Duenas-Pareja Y, Lopez-Martin S, Garcia-Garcia J, Melchor R, Rodriguez-Nieto MJ, Gonzalez-Mangado N, Peces-Barba G: Non-invasive ventilation in patients with severe hypercapnic encephalopathy in a conventional hospital ward. Arch Bronconeumol 2002, 38:372-375.

58. Plant PK, Owen $J L$, Elliott MW: Early use of non-invasive ventilation for acute exacerbations of chronic obstructive pulmonary disease on general respiratory wards: a multicentre randomised controlled trial. Lancet 2000, 355:1931-1935.

59. Ambrosino N, Foglio K, Rubini F, Clini E, Nava S, Vitacca M: Non-invasive mechanical ventilation in acute respiratory failure due to chronic obstructive pulmonary disease: correlates for success. Thorax 1995, 50:755-757.

60. Miller D, Fraser K, Murray I, Thain G, Currie GP: Predicting survival following non-invasive ventilation for hypercapnic exacerbations of chronic obstructive pulmonary disease. Int J Clin Pract 2012, 66:434-437.

61. Crummy F, Buchan C, Miller B, Toghill J, Naughton MT: The use of noninvasive mechanical ventilation in COPD with severe hypercapnic acidosis. Respir Med 2007, 101:53-61.

62. Phua J, Kong K, Lee KH, Shen L, Lim TK: Noninvasive ventilation in hypercapnic acute respiratory failure due to chronic obstructive pulmonary disease vs. other conditions: effectiveness and predictors of failure. Intensive Care Med 2005, 31:533-539.

63. Phua J, Ang YL, See KC, Mukhopadhyay A, Santiago EA, Dela Pena EG, Lim TK: Noninvasive and invasive ventilation in acute respiratory failure associated with bronchiectasis. Intensive Care Med 2010, 36:638-647.

64. Carratu P, Bonfitto P, Dragonieri S, Schettini F, Clemente R, Di Gioia G, Loponte L, Foschino Barbaro MP, Resta O: Early and late failure of noninvasive ventilation in chronic obstructive pulmonary disease with acute exacerbation. Eur J Clin Invest 2005, 35:404-409.

65. Scala R, Bartolucci S, Naldi M, Rossi M, Elliott MW: Co-morbidity and acute decompensations of COPD requiring non-invasive positive-pressure ventilation. Intensive Care Med 2004, 30:1747-1754

66. Chakrabarti B, Angus RM, Agarwal S, Lane S, Calverley PM: Hyperglycaemia as a predictor of outcome during non-invasive ventilation in decompensated COPD. Thorax 2009, 64:857-862.

67. Haja Mydin H, Murphy S, Clague H, Sridharan K, Taylor IK: Anemia and performance status as prognostic markers in acute hypercapnic respiratory failure due to chronic obstructive pulmonary disease. Int J Chron Obstruct Pulmon Dis 2013, 8:151-157.

68. Aso H, Kondoh Y, Taniguchi H, Kimura T, Nishiyama O, Kato K, Kataoka K, Hasegawa Y: Noninvasive ventilation in patients with acute exacerbation of pulmonary tuberculosis sequelae. Intern Med 2010, 49:2077-2083.

69. Nava S, Grassi M, Fanfulla F, Domenighetti G, Carlucci A, Perren A, Dell'Orso D, Vitacca M, Ceriana P, Karakurt Z, Clini E: Non-invasive ventilation in elderly patients with acute hypercapnic respiratory failure: a randomised controlled trial. Age Ageing 2011, 40:444-450

70. Roche Campo F, Drouot X, Thille AW, Galia F, Cabello B, d'Ortho MP Brochard L: Poor sleep quality is associated with late noninvasive ventilation failure in patients with acute hypercapnic respiratory failure. Crit Care Med 2009, 38:477-485.

71. Hill NS: Where should noninvasive ventilation be delivered? Respir Care 2009, 54:62-70.

72. Girou E, Brun-Buisson C, Taille S, Lemaire F, Brochard L: Secular trends in nosocomial infections and mortality associated with noninvasive ventilation in patients with exacerbation of COPD and pulmonary edema. JAMA 2003, 290:2985-2991. 
73. Jolliet $P$, Abajo B, Pasquina P, Chevrolet JC: Non-invasive pressure support ventilation in severe community-acquired pneumonia. Intensive Care Med 2001, 27:812-821.

74. Maheshwari V, Paioli D, Rothaar R, Hill NS: Utilization of noninvasive ventilation in acute care hospitals: a regional survey. Chest 2006, 129:1226-1233.

75. Carteaux G, Lyazidi A, Cordoba-Izquierdo A, Vignaux L, Jolliet P, Thille AW, Richard JC, Brochard L: Patient-ventilator asynchrony during noninvasive ventilation: a bench and clinical study. Chest 2012, 142:367-376.

76. Hilbert G, Gruson D, Gbikpi-Benissan G, Cardinaud JP: Sequential use of noninvasive pressure support ventilation for acute exacerbations of COPD. Intensive Care Med 1997, 23:955-961.

77. Branson RD, Gentile MA: Is humidification always necessary during noninvasive ventilation in the hospital? Respir Care 2010, 55:209-216

doi:10.1186/1471-2466-14-19

Cite this article as: Ozyilmaz et al:: Timing of noninvasive ventilation

failure: causes, risk factors, and potential remedies. BMC Pulmonary Medicine 2014 14:19.

\section{Submit your next manuscript to BioMed Central and take full advantage of:}

- Convenient online submission

- Thorough peer review

- No space constraints or color figure charges

- Immediate publication on acceptance

- Inclusion in PubMed, CAS, Scopus and Google Scholar

- Research which is freely available for redistribution 